\title{
New Regulations for the Natural Sciences Tripos
}

$\mathrm{T}$ HE Committee of the Natural Sciences Tripos at Cambridge has issued a report on the regulations for that Tripos. The changes suggested in Part $I$ are consequential on the recommendations of the Syndicate on Medical Courses and Examinations. New half subjects are introduced in biochemistry, physical and inorganic chemistry, organic chemistry, pathology and zoology (mathematics is already a half subject). Every candidate must take at least three whole subjects or at least two whole subjects and two half subjects.

Anatomy (a whole subject) is to consist of approximately equal proportions of topographical anatomy and scientific anatomy (embryology and morphology). A broad, rather than a detailed, knowledge of topographical anatomy will be required. The questions will deal manly with the general architecture of the body and will not require a detailed knowledge, except of the more important areas. In the papers on physiology there are to be some optional questions on pharmacology, but it will be possible to obtain full marks in physiology without attempting any questions in pharmacology.

The half subject pathology is to be treated from the point of view of abnormal biology and is to include the variations which may occur in the structure and functions of living tissues and organs, together with the biology of parasites, bacteria and viruses. In the half subject biochemistry, a know. ledge of the chemical processes associated with the normal life and growth of animal and vegetable organisms including micro-organisms is required.

In Part II, one of the four papers in geology and in mineralogy and petrology is to be common to both subjects. Candidates in geology may substitute one of the papers in mineralogy for one of the papers in geology and vice versa. Candidates in physiology may substitute for a specified paper in physiology a paper in pharmacology or for two specified papers in physiology two papers in experimental psychology.

In Part II (chemistry), the first two papers will be of such a nature as to test the candidates' knowledge of general chemical science. The third and fourth papers will be set so as to enable candidates to show a specialised knowledge of some of the subdivisions of chemistry. They will include questions in inorganic, organic, theoretical and physical chemistry, colloid science, metallurgy, crystal chemistry; and candidates will be allowed complete freedom of choice in the questions which they attempt. A sufficient number of questions will be set in each of the subdivisions for a candidate to attain the standard of the first class by answering questions in one or more of them.

In Part II (physics), the first three papers will be of such a nature as to test the candidates' general knowledge of physics. The fourth paper will be of such a nature as to enable candidates to show a specialised knowledge of some branches of physics. This will contain a large choice of questions so that it will not be necessary for a candidate to have a specialised knowledge of all branches of the subject. This paper will include a sufficient number of questions on crystallography and crystal physics for a candidate to be able to gain full marks on the paper by answering questions on those branches only.

\section{Russian Studies of the Stratosphere*}

$\mathrm{P}^{\mathrm{L}}$ ANS for the ascent into the stratosphere in the U.S.S.R. were first made in December 1932, and after various preparations the actual ascent was made on September 30,1933 , by G. A. Prokofiev, K. D. Godunov and Birnbaum. A height of nearly 19,000 metres was reached. The Central Geophysical Observatory has now issued a report in Russian of the ascent.

The original intention was to take measurements of the pressure and temperature of air, intensity and hardness of cosmic rays, intensity of electric field, conductivity of atmosphere, intensity of solar radiations, and analyses of the air, at various heights. It was, however, decided that in order not to overburden the balloon with the weight of all the necessary apparatus, the measurements of the intensity of electric field and solar radiation, as well as the observations on the conductivity of air, were to be postponed to the subsequent ascents.

The intensity of cosmic rays was measured by means of a Kolhörster electrometer, made of iron, volume $4,200 \mathrm{~cm} .^{3}$ and electrostatic capacity $0.35 \mathrm{~cm}$. During the ascent, the electrometer was charged by means of an ebonite rod. Measurements were made between the heights of 9,600 metres and 15,900 metres; the maximum possible error was estimated

* The Central Geophysical Observatory and the Ascent into the Stratosphere on September 30,1933. A collection of articles (in Russian) by various authors. Pp. 26. Leningrad, 1934. 1 rub. as 5 per cent. The results obtained show fair agreement with Prof. Piccard's observations but there is a discrepancy of more than 30 per cent with the results of Prof. Regener.

\begin{tabular}{|c|c|c|c|c|c|}
\hline \multicolumn{2}{|c|}{$\begin{array}{c}\text { Prof. Regener's } \\
\text { observations }\end{array}$} & \multicolumn{2}{|c|}{$\begin{array}{l}\text { Prof. Piccard's } \\
\text { observations }\end{array}$} & \multicolumn{2}{|c|}{$\underset{\text { observations }}{\text { Russian }}$} \\
\hline $\begin{array}{c}\text { Pressure } \\
\text { in } \mathbf{m m} . \\
\mathbf{H g} .\end{array}$ & $\begin{array}{l}\text { Intensity } \\
\text { of cosmic } \\
\text { rays }\end{array}$ & $\begin{array}{c}\text { Pressure } \\
\text { in mm. } \\
\mathbf{H g} .\end{array}$ & $\begin{array}{l}\text { Intensity } \\
\text { of cosmic } \\
\text { rays }\end{array}$ & $\begin{array}{c}\text { Pressure } \\
\text { in } \mathrm{mm} . \\
\mathbf{H g} .\end{array}$ & $\begin{array}{c}\text { Intensity } \\
\text { of cosmic } \\
\text { rays }\end{array}$ \\
\hline $\begin{array}{r}150 \\
100 \\
75\end{array}$ & $\begin{array}{c}\text { ions } / \mathrm{cm}^{3} / \\
\text { sec. } \\
153 \\
224 \\
243\end{array}$ & $\begin{array}{c}142 \\
127 \\
88 \cdot 5 \\
83\end{array}$ & $\begin{array}{c}\text { ions/cm. }{ }^{3} / \\
\text { sec. } \\
215 \\
248 \\
305 \\
313\end{array}$ & $\begin{array}{r}137 \\
86\end{array}$ & $\begin{array}{c}\text { ions } / \mathrm{cm} . \\
\text { sec. } \\
221 \\
345 \cdot 3\end{array}$ \\
\hline
\end{tabular}

In order to measure the hardness of cosmic rays, a specially adapted Hesse electrometer was used, volume $1,100 \mathrm{~cm}^{3}$, electrostatic capacity $1.2 \mathrm{~cm}$. The electrometer was charged again by an ebonite rod, and was placed in a lead filter, with a wall thickness of $30 \mathrm{~mm}$. The first set of measurements was taken at the height of $17,500-17,900$ metres, when the electrometer was covered by the lead filter on all sides. The ionisation found was 338 ions per c.c. per sec., with a possible maximum error estimated at 8 per cent. A second set of measure. ments was taken at the height of $17,400-17,900$ 